\title{
Young FADOI internists: from evidence to clinical practice
}

\author{
Paola Gnerre, ${ }^{1}$ Maurizia Gambacorta ${ }^{2}$ \\ ${ }^{1}$ UOC Medicina Interna, Ospedale San Paolo, Savona; ${ }^{2}$ UOC Medicina Interna, Ospedale Media Valle del Tevere, Todi (PG), \\ Italy
}

One of the activities implemented by the young FADOI internists in collaboration with the FADOI group of clinical governance concerns the preparation of monographs for the management of the most common pathologies of internal medicine.

Thus it was born a new journal section called Young FADOI internists: from evidence to clinical practice, which you can find in any publication of Italian Journal of Medicine. Each monograph consists of two chapters.

The first chapter contains epidemiologist, clinical, diagnostic and treatment aspects of the topic obtained from reviews or original articles. Among instrumental examinations particular attention is given to echo-bed side with the main ultrasound abnormalities that can be found. Subsequently in order to provide evidencebased recommendations for the practical management of the topic we evaluate the existence of guidelines about the matter. Therefore, we conduct a search using the following database-guidelines:

- Scottish Intercollegiate Guidelines Network (SIGN);

- Institute for Clinical System Improvement (ICSI);

- National Institute for Health and Clinical Excellence

(NICE) (NHS evidence);

- National Guideline Cleringhouse;

- Canadian Medical Association, CMA Infobase;

- New Zeland Guidelines Group;

Correspondence: Paola Gnerre, Ospedale San Paolo, via Genova 30,17100 Savona, Italy.

Tel.: +30.019.8404082.

E-mail: pgnerre@yahoo.it

Key words: Young FADOI internists; new journal section.

Received for publication: 19 January 2015.

Revision received: 20 January 2015.

Accepted for publication: 20 January 2015.

This work is licensed under a Creative Commons Attribution NonCommercial 3.0 License (CC BY-NC 3.0).

CCopyright P. Gnerre and M. Gambacorta, 2015

Licensee PAGEPress, Italy

Italian Journal of Medicine 2015; 9:94-95

doi:10.4081/itjm.2015.595
- National Sistem Guidelines;

- Clinical Practice Guidelines Portal;

- eGuidelines.

The research is carried out independently by all authors, using as key words terms related to the disease, which is the subject of the monograph when the site includes the search function, and in other cases we list the last guidelines manually stored in the database. The results obtained separately are then compared and discussed together. The guidelines thus obtained are evaluated using the AGREE instrument (Appraisal of Guidelines, Research and Evaluation II, 22) ${ }^{1}$ by all authors independently. AGREE II assesses compliance with 23 requirements, meeting 6 domains as the explanation of the purpose, the clarity, the involvement of all stakeholders, the rigor of development, applicability and editorial independence of the same. Each author assesses the compliance of individual requirements with a score from 1 (complete disagreement) to 7 (complete agreement). The scores assigned by each author are added within individual domains and reported with the highest and the lowest score possible within the domain based on the number of requirements included and the number of evaluators.

The last chapter includes a discussion with aspects of clinical governance related to the topic.

Our works are neither reviews nor position papers. The objective of our works is to provide evidencebased recommendations for the proper practical management of various topics by multi-parametric analysis of the guidelines available to date.

Today the baggage of the internist not only needs clinical competence ${ }^{2}$ but also skills of ultrasound and clinical governance. The concept of ultrasound stethoscope $^{3}$ is taking shape as a real instrument easy to apply in clinical practice at the bedside (technical Bedside side) and it can provide additional information with respect to classic physical examination.

The clinical governance 4 is not distinct from the clinical practice but it unifies the perspective of the clinical and economic health system performances. A tool for the clinician to continuously improve the quality of care focusing on excellence clinic.

Finally this work is a chance of growth for the 
young internist acquiring skills by methodological rigor. If you want to join our group contact us via email at pgnerre@yahoo.it.

\section{References}

1. AGREE Next Steps Consortium. Appraisal of Guidelines for Research \& Evaluation II - AGREE II Instrument; May 2009. Available from: http://www.agreetrust.org/wp-
content/uploads/2013/10/AGREE-II-Users-Manual-and23-item-Instrument_2009_UPDATE_2013.pdf

2. Palsson R, Kellet J, Lindgren S, et al. Core competencies of the European Internist: a discussion paper. Eur $\mathrm{J}$ Intern Med 2007;18:104-8.

3. Solomon SD, Saldana F. Point-of-care ultrasound in medical education - stop listening and look. N Engl J Med 2014;370:1083-5.

4. Scally G, Donaldson L. Clinical governance and the drive for quality improvement in the new NHS in England. BMJ 1998;317:61. 